\title{
Adenine, guanine and pyridine nucleotides in blood during physical exercise and restitution in healthy subjects
}

\author{
W. Dudzinska $\cdot$ A. Lubkowska $\cdot$ B. Dolegowska $\cdot$ \\ K. Safranow $\cdot$ K. Jakubowska
}

Accepted: 22 July 2010/Published online: 17 August 2010

(C) The Author(s) 2010. This article is published with open access at Springerlink.com

\begin{abstract}
Maximal physical exertion is accompanied by increased degradation of purine nucleotides in muscles with the products of purine catabolism accumulating in the plasma. Thanks to membrane transporters, these products remain in an equilibrium between the plasma and red blood cells where they may serve as substrates in salvage reactions, contributing to an increase in the concentrations of purine nucleotides. In this study, we measured the concentrations of adenine nucleotides (ATP, ADP, AMP), inosine nucleotides (IMP), guanine nucleotides (GTP, GDP, GMP), and also pyridine nucleotides (NAD, NADP) in red blood cells immediately after standardized physical effort with increasing intensity, and at the 30th min of rest. We also examined the effect of muscular exercise on adenylate (guanylate) energy charge-AEC (GEC), and on the concentration of nucleosides (guanosine, inosine, adenosine) and hypoxanthine. We have shown in this study that a standardized physical exercise with increasing intensity leads to an increase in IMP concentration in red
\end{abstract}

Communicated by Susan Ward.

W. Dudzinska $(\bowtie) \cdot$ A. Lubkowska

Department of Physiology, Faculty of Natural Sciences

of Szczecin University, Al. Piastów 40b,

71-065 Szczecin, Poland

e-mail: wiola@univ.szczecin.pl

A. Lubkowska $\cdot$ K. Safranow $\cdot$ K. Jakubowska

Department of Biochemistry and Medical Chemistry,

Pomeranian Medical University, Al. Powstancow

Wielkopolskich 72, 70-111 Szczecin, Poland

B. Dolegowska

Department of Laboratory Diagnostics and Molecular Medicine,

Pomeranian Medical University, Powstancow Wielkopolskich

72, 70-111 Szczecin, Poland blood cells immediately after the exercise, which with a significant increase in Hyp concentration in the blood suggests that Hyp was included in the IMP pool. Restitution is accompanied by an increase in the ATP/ADP and ADP/AMP ratios, which indicates an increase in the phosphorylation of AMP and ADP to ATP. Physical effort applied in this study did not lead to changes in the concentrations of guanine and pyridine nucleotides in red blood cells.

Keywords Exercise $\cdot$ Purine and pyrimidine nucleotides . Erythrocyte $\cdot$ Metabolism

\section{Introduction}

Purine metabolism involves synthesis and degradation of purine nucleotides, and determines the adenylate and guanylate pool value. In this way, it is responsible for the absolute value of intracellular ATP and GTP concentrations. The unique erythrocyte structure and metabolism is due to, among others, a deficiency of glutamine 5 -phosphoribosyl 1-pyrophosphate (PRPP) amidotransferase (EC 2.4.2.14) and its inability to synthesize purine nucleotides in the de novo pathway. Thus, in erythrocytes these compounds are formed in the reactions of reutilization, i.e. the reutilization of free purine bases (adenine, Ade; hypoxanthine, Hyp; guanine, Gua) and nucleosides (adenosine, Ado; inosine, Ino; guanosine, Guo). The reutilization of purine nucleosides and bases is a source of erythrocyte purine mononucleotides. The metabolic aim of these reactions is the introduction of these compounds into the high energy purine nucleotide synthesis pathways (ATP, ADP, GTP and GDP) (Dudzinska et al. 2006). The purine metabolism pathways are presented in Fig. 1. 


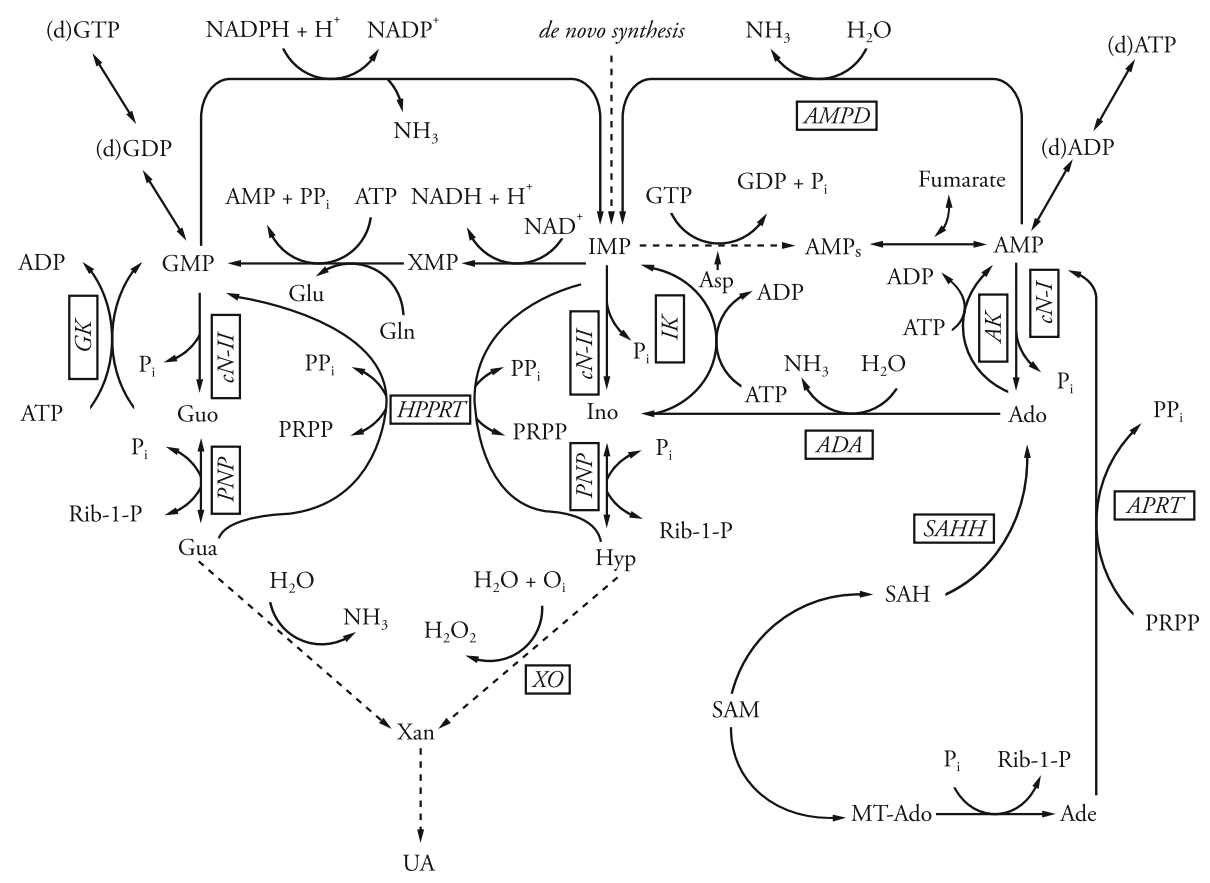

Fig. 1 Overview of purine metabolism in human erythrocytes (straight line) and out of them (dotted line). Based on Simmonds et al. 1988 and Smolenski et al. 1991, 1992. ADA adenosine deaminase (EC 3.5.4.4), $A K$ adenosine kinase (EC 2.7.1.20), AMPD AMP deaminase (EC 3.5.4.6), APRT adenine phosphoribosyltranferase (EC 2.4.2.7), $c N-I$ cytosolic AMP-specific 5'-nucleotidase (EC 3.2.3.5), $c N$-II cytosolic IMP and GMP-specific $5^{\prime}$-nucleotidase (EC

Physical exercise causes an oxygen deficit in the working muscles. The evolving hypoxia impairs oxidative ATP resynthesis, which increases ATP degradation, accompanied by the accumulation of IMP (Stathis et al. 1994; Hellsten et al. 1999). Most of the IMP is very quickly resynthesized to ATP during restitution, but part of the IMP is dephosphorylated which results in the production of Ino and Hyp (Stathis et al. 1994). The products of purine catabolism, not recovered intramuscularly via purine salvage, efflux the muscle and are collected in the plasma (Bangsbo et al. 1992; Hellsten-Westing et al. 1994; Zhao et al. 2000). Thanks to membrane transporters, nucleosides and purine bases (mainly hypoxanthine) are in equilibrium between plasma and red blood cells where they constitute the substrate in the salvage reactions. These processes involve PRPP, adenine phosphoribosyltransferase (APRT), hypoxanthine-guanine phosphoribosyltransferase (HGPRT) and nucleoside kinases (Dudzinska et al. 2006).

Many in vitro studies have shown that nucleosides and purine bases may participate in the resynthesis of adenine nucleotides in red blood cells (Bontemps et al. 1986; Berman et al. 1988; Van der Berghe and Bontemps 1990; Kim 1990; Komarova et al. 1999). Kim (1990) and Komarova et al. (1999) demonstrated the participation of adenosine in the resynthesis of the adenine nucleotide pool,
3.2.3.5), GK guanosine kinase (EC 2.7.1.73), HGPRT hypoxanthineguanine phosphorybosyltransferase (EC 2.4.2.8), $I K$ inosine kinase (EC 2.7.1.73), MTAdo methylothioadenosine, 5'-NT-5'-nucleotidase (EC 3.1.3.5), PNP purine nucleoside phosphorylase (EC 2.4.2.1), PRPP 5'-phosphoribosyl 1-pyrophosphate, SAH S-adenosylhomocysteine, $S A H H$ S-adenosylhomocysteine hydrolase (EC 3.3.1.1), SAM S-adenosylmethionine

especially under conditions of high $\mathrm{P}_{\mathrm{i}}$ concentrations. The results of those experiments suggest the participation of $\mathrm{P}_{i}$ in the stimulation of adenosine kinase. In contrast, Van der Berghe and Bontemps (1990) and Bontemps et al. (1986) reported an $\mathrm{P}_{\mathrm{i}}$-induced inhibition of the activity of $5^{\prime}$-nucleotidase and AMP deaminase. Thus, the increase in erythrocyte and plasma $\mathrm{P}_{\mathrm{i}}$ accompanying physical effort (Yamamoto et al. 1994) may lead to changes in the activities of enzymes involved in purine metabolism. In addition, one of the phenomena regularly associated with intense physical effort is metabolic acidosis.

The increase in the concentration of hydrogen ions in body fluids is greater, the greater the intensity of effort. A fall in $\mathrm{pH}$ in red blood cells results in a decrease in ADP and 2.3 DPG (allosteric inhibitors of PRPP synthetase, EC 2.7.6.1) with a concomitant increase in intracellular $P_{i}$ (activator of PRPP synthetase) and ATP (Berman et al. 1988). Thus, intense physical activity is likely to encourage increased synthesis of PRPP - a co-substrate in reactions catalyzed by APRT and HGPRT. Berman et al. (1988) reported that the uptake of Hyp and accumulation of IMP in red blood cells are significantly increased at an acid $\mathrm{pH}$, high external phosphate concentrations, and low $\mathrm{P}_{\mathrm{O}_{2}}$. In addition, they suggested that erythrocytes could play a role in the removal of Hyp from anoxic tissue. 
So far, there has been few reports of post-exercise changes in the erythrocyte concentration of adenine, guanine, and pyridine nucleotides. Moreover, existing literature is very inconsistent in this respect (Makarewicz et al. 1980; Harkness et al. 1983; Yamamoto et al. 1994). Therefore, we decided to measure the concentrations of adenine (ATP, ADP, AMP) inosine (IMP), guanine (GTP, GDP, GMP), as well as pyridine (NAD, NADP) nucleotides in red blood cells immediately after standardized physical effort with increasing intensity, and at the 30th min of rest. We examined the effect of muscular exercise on the adenylate (guanylate) energy charge-AEC (GEC), and on the concentration of nucleosides (guanosine, inosine, adenosine) and hypoxanthine.

\section{Methods}

\section{Subjects}

Twenty-two healthy male subjects volunteered to participate in his study. Their age, height, weight, and peak oxygen consumption were $21.9 \pm 2.33$ years, $179.8 \pm$ $8.33 \mathrm{~cm}, 75.6 \pm 7.89 \mathrm{~kg}$ and $45.8 \pm 4.11 \mathrm{ml} \mathrm{kg}^{-1} \mathrm{~min}^{-1}$, respectively.

The subjects were fully informed of any risks and discomfort associated with the experimental procedures before giving their consent to participate. The study was approved by the local ethics committee.

\section{Exercise protocol}

The examined individuals were subjected to a continuous effort test with progressively increasing intensity (up to a refusal) on a cycloergometer (Kettler X-7, Germany). The test was preceded by a 5-min warm-up on the cycloergometer $(25 \mathrm{~W})$. The test proper began at a resistance of $70 \mathrm{~W}$ while maintaining 70 revolutions per min. The effort continued with an increasing load (20 W every $3 \mathrm{~min}$ ) until refusal, or until the tested individual was not able to maintain the required frequency of rotation. In the last $15 \mathrm{~s}$ of each 3-min effort at a given load, arterialized blood was collected to assess lactate concentration. Lactate levels were determined during the exercise and were used to establish an individual lactic threshold. Lactate concentration was determined using a Dr Lange Lp-20 kit (Lange, Germany). A heart rate monitor (Polar S610, Finland) was used to record resting heart rate and changes during exercise. The uptake of oxygen during exercise was examined using an Oxycon gas analyzer (Jaeger, Germany).

Based on the heart rate increase curve and the lactic acid concentrations at subsequent loads, we wanted to determine the load that was followed by a significant increase in
Table 1 Anthropometrical and physiological characteristics of subjects

\begin{tabular}{lc}
\hline Parameters & Mean \pm SD \\
\hline Body height (cm) & $179.8 \pm 8.33$ \\
Body mass (kg) & $75.6 \pm 7.89$ \\
$\mathrm{HR}_{\text {rest }}(\mathrm{bpm})$ & $72.1 \pm 8.03$ \\
$\mathrm{HR}_{\text {max }}(\mathrm{bpm})$ & $195.6 \pm 6.60$ \\
PPA (W) & $134.5 \pm 26.39$ \\
$\mathrm{MPO}(\mathrm{W})$ & $218 \pm 40.77$ \\
$\mathrm{VO}_{2 \max }(\mathrm{ml} / \mathrm{min} / \mathrm{kg})$ & $45.8 \pm 4.11$ \\
\hline
\end{tabular}

Values are given as mean $\pm \mathrm{SD} ; n=22$

$H R$ heart rate, $P P A$ anaerobic threshold, $M P O$ maximum power output, $V O_{2 \max }$ maximum of oxygen uptake

blood lactate concentration. Individual lactate threshold was calculated using the plot of log LA linear regression and $\log$ of the effort intensity.

The selection of loads was aligned with the power achieved at corresponding lactic thresholds (PPA). Table 1 shows the anthropometric and physiological parameter characteristics of the study.

Blood analysis

Concentrations of purine and pyridine nucleotides, guanosine (Guo), Inosine (Ino), adenosine (Ado) and hypoxanthine (Hyp) were determined in whole blood using high-performance liquid chromatography. Designations were made of the blood taken from the antecubital vein immediately before and after exercise, and $30 \mathrm{~min}$ after exercise testing.

The samples $(500 \mu \mathrm{L})$ of heparinized blood were deproteinized with an equal volume of $1.3 \mathrm{M} \mathrm{HClO}_{4}$, mixed, and then centrifuged at $20,000 \mathrm{~g}$ for $5 \mathrm{~min}$ at $4^{\circ} \mathrm{C}$. The supernatant $(400 \mu \mathrm{L})$ was neutralized with $130-160 \mu \mathrm{L}$ of $1 \mathrm{M} \mathrm{K}_{3} \mathrm{PO}_{4}$ (to $\mathrm{pH} 5-7$ ). The neutralized extract was again centrifuged as above, and the supernatant was stored at $-80^{\circ} \mathrm{C}$ until analysis.

Chromatographic analysis was performed using a Hewlett-Packard series 1100 chromatograph according to the method used by Smolenski et al. (1990), a modification of Bober et al. (2003). The concentrations of nucleotides (ATP, ADP, AMP, IMP, GTP, GDP, GMP), Guo, Ino, Ado and Hyp were determined in the whole blood. We also calculated the value of TAN and TGN, and AEC and GEC. Taking into account, the hematocrit values (hematocrit values were determined in duplicate by the standard microhematocrit method and expressed in percentage), we were able to calculate the intraerythrocyte nucleotide concentrations ( $\mu \mathrm{mol} / \mathrm{l} \mathrm{RBC}$ ) with the assumption that there were no significant concentrations in plasma due to the action of the nucleotidases. The concentrations of 
nucleosides (Ino, Ado, Guo) and oxypurine (Hyp), which are present in both erythrocytes and plasma, are expressed as $\mu \mathrm{mol} / 1$ whole blood. They are not directly comparable to concentrations measured in separated erythrocytes or plasma.

Inorganic phosphorous in plasma was determined using a Randox Laboratory Diagnostic kit REF PH1016 (Randox Laboratories Ltd, Co. Antrim, UK).

\section{Statistical analysis}

All values are reported as mean \pm SD. ANOVA with repeated measurements was used to compare data over time. When the ANOVA was significant (RIR) Tukey's post hoc tests were used to localize the difference. The accepted level of significance was defined as $P<0.05$. In order to demonstrate whether the observed correlations were statistically significant, Spearman's rank correlation coefficient was applied.

\section{Results}

The characteristics of some anthropometrical and physiological parameters are shown in Table 1. In the group of subjects, the testing time was $24.0 \pm 5.97 \mathrm{~min}$, HR recorded before the exercise was $72.1 \pm 8.03$ beats $/ \mathrm{min}$, while the maximum was $195.6 \pm 6.60 \mathrm{beats} / \mathrm{min}$. The maximum power value was $218 \pm 40.77 \mathrm{~W}$, while the anaerobic threshold was set at $134.5 \pm 26.39 \mathrm{~W}$. In the examined group, the oxygen consumption at maximum load was $45.8 \pm 4.11 \mathrm{ml} / \mathrm{min} / \mathrm{kg}$, which indicates that the subjects had a good aerobic endurance for this age group in comparison with reference data (Astrand and Rodhal 1986).
The mean and standard deviation of guanine and pyridine nucleotides concentrations are presented in Table 2 There were no significant changes in the concentrations of GTP, GDP, GMP and TGN in red blood cells immediately after exercise, and at the 30th $\mathrm{min}$ of recovery. No significant changes were observed for GEC nor the concentrations of NAD and NADP.

ATP, ADP, and AMP stoichiometrically couple all of the metabolic sequences of a living cell. The amount of metabolically available energy that is momentarily stored in the adenylate system is linearly related to the mole fraction of ATP plus half the mole fraction of ADP; this parameter has been termed the AEC of the adenylate pool. In this study, physical exercise with increasing intensity did not contribute to significant changes in ATP concentration in red blood cells immediately after exercise and at the 30th $\min$ of recovery (Table 3 ). We demonstrated a significantly lower $(P<0.01)$ concentration of ADP in red blood cells at the 30th min of recovery in comparison to concentrations observed immediately before the test. Similarly, the concentration of AMP in red blood cells was significantly lower on the 30th min of recovery. At the same time, the decrease observed in the concentration of AMP was significant both with respect to the levels observed immediately before exercise $(P<0.0001)$ and immediately after exercise $(P<0.001)$. Physical exercise with increasing intensity contributed to a significant increase in IMP concentration in red blood cells compared to resting levels $(P<0.01)$. At the 30th min of rest, we observed a significant decrease in the concentration of IMP in comparison to its level immediately after the exercise $(P<0.01)$. AEC was significantly higher at the 30th min of recovery, both in comparison to the value observed before $(P<0.006)$ and immediately after exercise $(P<0.01)$ (Table 3).

Table 2 Concentration of guanine nucleotides (GTP, GDP, GMP) and pyridine nucleotides (NAD, NADP) in red blood cells before exercise, after exercise and $30 \mathrm{~min}$ of recovery

\begin{tabular}{lccc}
\hline & Before exercise & After exercise & 30 min of recovery \\
\hline GTP $(\mu \mathrm{mol} / \mathrm{l} \mathrm{RBC})$ & $66.80 \pm 8.25$ & $65.27 \pm 7.41$ & $63.01 \pm 8.02$ \\
GDP $(\mu \mathrm{mol} / \mathrm{l} \mathrm{RBC})$ & $28.02 \pm 4.55$ & $29.04 \pm 6.23$ & $28.42 \pm 6.67$ \\
GMP $(\mu \mathrm{mol} / \mathrm{l} \mathrm{RBC})$ & $41.46 \pm 6.29$ & $39.53 \pm 6.23$ & $41.08 \pm 6.31$ \\
TGN $(\mu \mathrm{mol} / \mathrm{l} \mathrm{RBC})$ & $133.84 \pm 12.26$ & $133.66 \pm 10.07$ & $132.49 \pm 12.76$ \\
GEC & $0.58 \pm 0.03$ & $0.59 \pm 0.03$ & $0.58 \pm 0.03$ \\
NAD $(\mu \mathrm{mol} / \mathrm{l} \mathrm{RBC})$ & $72.84 \pm 7.13$ & $72.88 \pm 9.55$ & $71.77 \pm 8.36$ \\
NADP $(\mu \mathrm{mol} / \mathrm{l} \mathrm{RBC})$ & $45.80 \pm 4.53$ & $45.18 \pm 3.40$ & $44.89 \pm 3.80$ \\
\hline
\end{tabular}

Concentrations of GTP, GDP, GMP, TGN, NAD, NADP are expressed as $\mu \mathrm{mol} / \mathrm{l} \mathrm{RBC}$

Values are given as mean $\pm \mathrm{SD} ; n=22$

TGN (total guanine nucleotides) $=[\mathrm{GTP}]+[\mathrm{GDP}]+[\mathrm{GMP}]$

GEC (guanylate energy charge) was evaluated according to the formula by Atkinson

$\mathrm{GEC}=([\mathrm{GTP}]+0.5[\mathrm{GDP}]) /([\mathrm{GTP}]+[\mathrm{GDP}]+[\mathrm{GMP}])$ 
Table 3 Concentrations of adenine nucleotides (ATP, ADP, AMP) and inosine nucleotides (IMP) in red blood cells before exercise, after exercise and $30 \mathrm{~min}$ of recovery

\begin{tabular}{lccc}
\hline & Before exercise & After exercise & 30 min of recovery \\
\hline ATP $(\mu \mathrm{mol} / \mathrm{l} \mathrm{RBC})$ & $1,797.00 \pm 158.83$ & $1,777.80 \pm 130.52$ & $1,808.522 \pm 155.26$ \\
ADP $(\mu \mathrm{mol} / \mathrm{l} \mathrm{RBC})$ & $227.42 \pm 40.49$ & $220.13 \pm 42.30$ & $189.18 \pm 39.57^{*}$ \\
AMP $(\mu \mathrm{mol} / \mathrm{l} \mathrm{RBC})$ & $14.25 \pm 2.94$ & $13.21 \pm 3.09$ & $9.77 \pm 2.43^{* * * \S \S}$ \\
TAN $(\mu \mathrm{mol} / \mathrm{l} \mathrm{RBC})$ & $2,038.59 \pm 172.87$ & $2,010.73 \pm 154.92$ & $2,006.79 \pm 171.29$ \\
AEC & $0.93 \pm 0.01$ & $0.93 \pm 0.01$ & $0.94 \pm 0.009^{* *, \S}$ \\
IMP $(\mu \mathrm{mol} / \mathrm{l} \mathrm{RBC})$ & $7.16 \pm 1.35$ & $8.43 \pm 1.86^{*}$ & $6.82 \pm 2.00^{\S}$ \\
ATP/ADP $(\mu \mathrm{mol} / \mathrm{l} \mathrm{RBC})$ & $8.13 \pm 1.54$ & $8.41 \pm 1.53$ & $9.91 \pm 1.96^{*}, \S$ \\
ADP/AMP $(\mu \mathrm{mol} / \mathrm{l} \mathrm{RBC})$ & $16.06 \pm 1.13$ & $16.95 \pm 1.84$ & $19.56 \pm 1.67 * * * \S \S$ \\
\hline
\end{tabular}

Concentrations of ATP, ADP, AMP, TAN and IMP are expressed as $\mu \mathrm{mol} / \mathrm{l} \mathrm{RBC}$

Values are given as mean $\pm \mathrm{SD} ; n=22$

TAN (total adenine nucleotides $)=[\mathrm{ATP}]+[\mathrm{ADP}])+[\mathrm{AMP}]$

AEC (adenylate energy charge) was evaluated according to the formula by Atkinson

$\mathrm{AEC}=([\mathrm{ATP}]+0.5[\mathrm{ADP}]) /([\mathrm{ATP}]+[\mathrm{ADP}]+[\mathrm{AMP}])$

$* P<0.01 ; * * P<0.006$; *** $P<0.0001$, significantly different from before exercise

$\S P<0.01 ;{ }^{\S \S} P<0.001 ;{ }^{\S \S} P<0.0001$, significantly different from after exercise

Table 4 Concentrations of guanosine, inosine, adenosine and hypoxanthine in blood before exercise, after exercise and 30 min of recovery

\begin{tabular}{lccc}
\hline & Before exercise & After exercise & 30 min of recovery \\
\hline Guanosine (Guo) $\mu \mathrm{mol} / \mathrm{l}$ whole blood & $0.11 \pm 0.03$ & $0.14 \pm 0.03$ & $0.13 \pm 0.04$ \\
Inosine (Ino) $\mu \mathrm{mol} / \mathrm{l}$ whole blood & $0.11 \pm 0.03$ & $0.50 \pm 0.26$ & $1.12 \pm 0.59^{* * *, \S}$ \\
Adenosine (Ado) $\mu \mathrm{mol} / \mathrm{l}$ whole blood & $0.07 \pm 0.01$ & $0.08 \pm 0.01$ & $0.07 \pm 0.01$ \\
Hypoxanthine (Hyp) $\mu \mathrm{mol} / \mathrm{l}$ whole blood & $2.20 \pm 1.61$ & $16.25 \pm 7.86^{* * *}$ & $18.54 \pm 8.78^{* * *}$ \\
\hline
\end{tabular}

Concentrations of Guo, Ino, Ado and Hyp are expressed in $\mu \mathrm{mol} / \mathrm{l}$ whole blood

Values are given as mean $\pm \mathrm{SD} ; n=22$

*** $P<0.0001$, significantly different from before exercise

$\S P<0.01$, significantly different from after exercise

Table 4 shows concentrations of Ino, Hyp, Ado and Guo in the blood. Ino concentration measured in blood immediately after exercise reached $0.5 \pm 0.26 \mu \mathrm{mol} / \mathrm{L}$ and did not differ significantly from the value measured before exercise $(0.1 \pm 0.04 \mu \mathrm{mol} / \mathrm{L})$. Ino concentration was significantly higher $30 \mathrm{~min}$ after exercise, both in comparison to the resting value $(P<0.001)$ and after the effort $(P<0.001)$.

Physical exercise contributed to a nearly eightfold increase in Hyp concentration in the blood in relation to resting levels (from $2.2 \pm 1.61$ to $16.3 \pm 7.86 \mu \mathrm{mol} / \mathrm{L}$ ) $(P<0.0001)$. High concentrations of Hyp were observed even $30 \mathrm{~min}$ after the exercise $(18.5 \pm 8.78 \mu \mathrm{mol} / \mathrm{L})$, albeit this increase was still significant in relation to resting values $(P<0.0001)$ but not to post-exercise levels. There was no significant relationship between the concentration of Hyp in the blood and the concentration of IMP in red blood cells.

There were no significant changes in the concentrations of Ado and Guo in the blood after exercise and at the 30th min of rest.
The concentration of inorganic phosphorous measured before the exercise was $1.14 \pm 0.13 \mathrm{mM}$. Immediately after exercise it was $1.39 \pm 0.22 \mathrm{mM}$ and on the 30th min of restitution it was $1.46 \pm 0.28 \mathrm{mM}$, so in both times the concentration of the inorganic phosphorous significantly increased in comparison with resting values $(P<0.01)$.

\section{Discussion}

The post-exercise increase in the concentration of Ino and Hyp in the blood has already been observed by many researchers (Sutton et al. 1980; Hellsten-Westing et al. 1989; Bangsbo et al. 1992; Hellsten et al. 1999; Zhao et al. 2000). Many studies also demonstrated that Ino and Hyp are produced in muscles during moderate to intense exercise, while there is great individual variation of changes in plasma concentrations of Hyp induced by intense exercise (Sahlin et al. 1991; Bangsbo et al. 1992; Hellsten-Westing et al. 1993b). According to Bangsbo et al. (1992) and 
Hellsten-Westing et al. (1989), the serum levels of Hyp increased up to five times the resting levels after arm cranking and more than ten times after short distance postmaximum running. Hellsten-Westing et al. (1993a) and Sahlin et al. (1991) showed that the significant peak in the Hyp concentration appears $20 \mathrm{~min}$ after conclusion of the exercise. Hellsten et al. (1999) showed that $100 \mathrm{~s}$ after intense exercise, femoral venous Ino and Hyp concentrations had increased and significant net release of Hyp and Ino was observed after $70 \mathrm{~s}$. In recovery, venous Ino and Hyp increased further, and the release of Ino and Hyp peaked after 12-20 min and were still significant after 90 min of recovery.

A significant increase in Hyp concentration in the blood observed in this study immediately after the exercise and accompanied by no significant changes in the concentrations of Ino, exhibits differences in the rate of entry of these metabolites into the plasma. Zhao et al. (2000) in their studies of muscle adenine nucleotide metabolism during maximal exercise and in recovery from maximal exercise in humans showed a significant increase in the concentration of Hyp and Ino in plasma, respectively, at the 5th- and 10th min of recovery, while Hellsten et al. (1999) showed a multiple significant increase in plasma concentrations of Hyp immediately after high-intensity intermittent exercise. The differences in the rate of entry of these metabolites into the blood may be due, inter alia, to different scheme of the exercise or its duration.

However, in this study a significant increase in the concentration of extracellular markers of muscle adenine nucleotide catabolism (Ino and Hyp) indicates the occurrence of severe energy stress that occurred during exercise. The observed increase in the concentration of Hyp immediately after the exercise and at the 30th min of recovery, points to a significant increase in the degradation of ATP. The results show that Hyp was already released from working muscles during exercise, and also $30 \mathrm{~min}$ after its completion.

Our study shows a significant increase in IMP concentration in red blood cells immediately after exercise. These results confirm the increase in the post-exercise concentration of IMP observed by Yamamoto et al. (1994) and Makarewicz et al. (1980). However, they contradict the findings by Harkness et al. (1983), who after 2 min of intense physical exertion showed no increase in the concentration of erythrocyte IMP. One of the reasons for the differences may be the duration of the effort. As our research shows, 25 min of exercise with increasing intensity results in an increase in IMP concentration of red blood cells.

IMP concentration in red blood cells is the result of the synthesis and degradation of this nucleotide. One of the reasons leading to an increase in IMP concentration in red blood cells may be a decrease in $\mathrm{pH}$, high external phosphate concentrations, and low $\mathrm{P}_{\mathrm{O}_{2}}$, it has been demonstrated that the IMP synthesis is regulated by $\mathrm{pH}$, inorganic phosphate and oxygen tension (Berman et al. 1988). As is clear from the study by Yamamoto et al. (1994), a 25-min exercise on a cycloergometer with increasing intensity until refusal leads to a significant increase in $\mathrm{P}_{\mathrm{i}}$ in red blood cells and plasma, and a decline in blood $\mathrm{pH}$. In our study we also showed a significant increase in $\mathrm{P}_{\mathrm{i}}$ in plasma, not only immediately after effort but also on the 30th min of restitution. Moreover, in vitro studies on the effects of inorganic phosphate on the concentration of nucleotides showed that in red blood cells incubated in a solution containing $2 \mathrm{mM} \mathrm{P}$, an increase in IMP concentration occurs (Yamamoto et al. 1994). Moreover, Berman et al. (1988) showed that the uptake of Hyp and accumulation of IMP in red blood cells are significantly increased at acidic $\mathrm{pH}$ levels, high external phosphate concentrations, and low $\mathrm{P}_{\mathrm{O}_{2}}$, the conditions that accompany intense physical effort.

Given the fact that one way of removing Hyp from blood is its uptake by red blood cells, the significant increase in Hyp concentration in the blood observed immediately after exercise, and the significant increase in IMP concentration in red blood cells suggests that Hyp was included in the IMP pool in a reaction catalysed by HGPRT. It does not seem that a significant increase in IMP concentration in red blood cells immediately after exercise was caused by the increased activity of AMP deaminase (EC 3.5.4.6). First, we did not observe a significant decrease in the concentration of AMP, which accompanies an increase in AMP deaminase activity (Tavazzi et al. 2000, 2001). Secondly, it has been shown that intense physical activity leads to the inhibition in AMP deaminase in skeletal muscle, caused directly by an increase in the concentration of orthophosphate and a decline in $\mathrm{pH}$ (Hellsten et al. 1999). It has also been demonstrated that $P_{i}$, IMP and 2.3 BPG are the inhibitors of the enzyme (Bontemps et al. 1986; Mosharov et al. 1998; Van den Berghe and Bontemps 1990). Thus, the increase in $\mathrm{P}_{\mathrm{i}}$ concentration in red blood cells, and a drop in blood $\mathrm{pH}$, as well as an increase in the concentration of IMP observed immediately after the exercise, suggest the inhibition of AMP deaminase. It seems that an irreversible reaction leading to the hydrolytic deamination of AMP to IMP in erythrocytes is inhibited because of the necessity to protect the cellular ATP.

It is known that under physiological conditions, the pool of adenine and guanine nucleotides is kept constant. The concentration ratio of individual nucleotides within this pool is maintained primarily by adenylate kinase, guanylate kinases, and enzymes involved in the catabolism of these compounds. Our study showed no erythrocyte changes in the concentration of adenine and guanine nucleotides 
immediately after exercise. Significant decreases in AMP and ADP in the absence of significant changes in ATP and TAN were observed only at the 30th min of rest, which confirms results from other authors (Makarewicz et al. 1980; Yamamoto et al. 1994; Skotnicka et al. 2008). Makarewicz et al. (1980) showed a significant decrease in AMP and ADP in red blood cells in the absence of significant changes in the concentration of ATP immediately after intense exercise and 30 min of rest. Yamamoto et al. (1994), incubating the red blood cells in a solution containing $2 \mathrm{mM} \mathrm{P} \mathrm{P}_{\mathrm{i}}$, showed a decrease in AMP and ADP in the absence of significant changes in the concentrations of ATP. In addition to the $\mathrm{P}_{\mathrm{i}}$-induced decrease in AMP and ADP in vitro, they showed a decline in AMP and ADP in red blood cells in the group of 6 healthy subjects after a 25-min bicycle exercise on a cycloergometer.

In our study, a drop in the concentration of AMP and ADP, with the simultaneous increase in ATP/ADP and ADP/AMP ratios after $30 \mathrm{~min}$ of rest indicates an increased phosphorylation AMP and ADP to ATP (Table 3). Although we observed no significant increase in ATP, an $8 \%$ increase in the concentration of this nucleotide was observed in red blood cells during recovery in comparison to resting values. Because the only source of erythrocyte ATP is glycolysis, it can be supposed that physical activity results in an increased rate of this conversion in erythrocytes.

In summary, it can be concluded that a standardized physical exercise with increasing intensity leads to an increase in IMP concentration in red blood cells immediately after exercise, which with a significant increase in Hyp concentration in the blood suggests that Hyp was included in the IMP pool. During the rest, an increase in ATP/ADP and ADP/AMP ratios occur, which indicates an increased phosphorylation of AMP and ADP to ATP. The exercise used in this study did not lead to erythrocyte changes in the concentration of guanosine and pyridine nucleotides.

Acknowledgments The study was supported by grant No. N404 281337 from the State Committee for Scientific Research.

Open Access This article is distributed under the terms of the Creative Commons Attribution Noncommercial License which permits any noncommercial use, distribution, and reproduction in any medium, provided the original author(s) and source are credited.

\section{References}

Astrand PO, Rodhal K (1986) Textbook of work physiology: physiological bases of exercise. McGraw-Hill, New York

Bangsbo J, Sjödin B, Hellsten-Westing Y (1992) Exchange of hypoxanthine in muscle during intense exercise in man. Acta Physiol Scan 146:528-533
Berman PA, Black DA, Human L, Harley EH (1988) Oxypurine cycle in human erythrocytes regulated by $\mathrm{pH}$, inorganic phosphate, and oxygen. J Clin Invest 82:980-986

Bober J, Kedzierska K, Safranow K, Kwiatkowska E, Jakubowska K, Herdzik E, Dolegowska B, Domanski L, Ciechanowski K (2003) Influence of glucose in dialyzing fluid on purine concentrations in hemodialyzed patients with chronic renal failure. Nephron Clin Pract 95:31-36

Bontemps F, Van den Berghe G, Hers G (1986) Pathways of adenine nucleotide catabolism in erythrocytes. J Clin Invest 77:824-830

Dudzinska W, Hlynczak AJ, Skotnicka E, Suska M (2006) The purine metabolism of human erythrocytes. Biochemistry (Mosc) 71:467-475

Harkness RA, Simmonds RJ, Coade SB (1983) Purine transport and metabolism in man: the effect of exercise on concentrations of purine bases, nucleosides and nucleotides in plasma, urine, leucocytes and erythrocytes. Clin Sci 64:333-340

Hellsten Y, Richter EA, Kiens B, Bangsbo J (1999) AMP deamination and purine exchange in human skeletal muscle during and after intense exercise. J Physiol 520:909-920

Hellsten-Westing Y, Ekblom B, Sjödin B (1989) The metabolic relation between hypoxanthine and uric acid in man following maximal short-distance running. Acta Physiol Scand 137:341-345

Hellsten-Westing Y, Balsom PD, Norman B, Sjödin B (1993a) Changes in plasma hypoxanthine and free radical markers during exercise in man. Acta Physiol Scand 149:405-412

Hellsten-Westing Y, Norman B, Balsom PD, Sjödin B (1993b) Decreased resting levels of adenine nucleotides in human skeletal muscle after high intensity training. J Appl Physiol 74:2523-2528

Hellsten-Westing Y, Ekblom B, Kajser I, Sjödin B (1994) Exchange of purines in human liver and skeletal muscle with short-term exhaustive exercise. Am J Physiol 266:81-86

Kim HD (1990) Is adenosine a second metabolic substrate for human red blood cells. Biochim Biophys Acta 1036:113-120

Komarova S, Mosharov EV, Vitvitski V, Ataullakhanov FI (1999) Adenine nucleotide synthesis in human erythrocytes depends on the mode of supplementation of cell suspension with adenosine. Blood Cell 25:170-179

Makarewicz K, Sysa J, Kedziora J, Cholewa M, Zakrzewska I, Górski L, Janiak A, Błaszczyk J (1980) Adenine nucleotides and 2, 3diphosphoglicerate in the erythrocytes during physical exercise and restitution in healthy subjects. Acta Physiol Pol 31:115-121

Mosharov EV, Vitvitsky VM, Ataullakhanow FI (1998) Product activation of human erythrocyte AMP deaminase. FEBS Lett 440:64-66

Sahlin K, Tonkonogi M, Söderlund K (1991) Plasma hypoxanthine and ammonia in humans during prolonged exercise. Eur J Appl Physiol 80:417-422

Simmonds HA, Fairbank LD, Morris GS, Webster R, Harley EH (1988) Altered erythrocyte nucleotide patterns are characteristic of inherited disorders of purine or pyrimidine metabolism. Clin Chim Acta 171:197-210

Skotnicka E, Baranowska-Bosiacka I, Dudzinska W, Suska M, Nowak R, Krupecki K, Hlynczak AJ (2008) The effect of exhaustive exercise on the concentration of purine nucleotides and their metabolites in erythrocytes. Biol Sport 25:35-55

Smolenski RT, Lachno DR, Ledingham SJM, Yacoub MH (1990) Determination of sixteen nucleotides, nucleosides and bases using high-performance liquid chromatography and its application to the study of purine metabolism in heart for transplantation. J Chromatogr 527:414-420

Smolenski RT, Montero C, Duley JA, Simmonds HA (1991) Effects of adenosine analogues on ATP concentrations in human erythrocytes. Biochem Pharmacol 42:1767-1773 
Smolenski RT, Fabianowska-Majewska K, Montero C, Duley JA, Fairbanks LD, Marlewski M, Simmonds HA (1992) A novel route of ATP synthesis. Biochem Pharmacol 43:2053-2057

Stathis CG, Febbraio MA, Carey MF, Snow RJ (1994) Influence of sprint training on human skeletal muscle purine nucleotide metabolism. J Appl Physiol 76:1802-1809

Sutton JR, Toews CJ, Ward R (1980) Purine metabolism during strenuous exercise in man. Metabolism 29:254-260

Tavazzi B, Di Piero D, Amorini AM, Fazina G, Tuttobene M, Giardina B, Lazzarino G (2000) Energy metabolism and lipid peroxidation of human erythrocytes as function of increased oxidative stress. Eur J Biochem 267:684-689

Tavazzi B, Amorisie AM, Fazino G, Di Pierro D, Tuttobene M, Giordina B, Lazzarino G (2001) Oxidative stress induces impairment of human erythrocyte energy metabolism through the oxygen radical-mediated direct activation of AMP-deaminase. J Biol Chem 276:48083-48092

Van den Berghe G, Bontemps F (1990) Adenine nucleotide catabolism in human erythrocytes: pathways and regulation. Biomed Biochim Acta 49:117-122

Yamamoto T, Moriwaki Y, Takahashi S, Ishizashi H, Higashino K (1994) Effect of muscular exercise by bicycle ergometer on erythrocyte purine nucleotides. Horm Metab Res 26:504-508

Zhao S, Snow RJ, Stathis G, Febbraio MA, Carey MF (2000) Muscle adenine nucleotide metabolism during and recovery from maximal exercise in humans. J Appl Physiol 88:1513-1519 